\title{
A Maturity Level-Based Assessment Tool to Enhance the Implementation of Industry 4.0 in Small and Medium-Sized Enterprises
}

\author{
Erwin Rauch $^{1}{ }^{\oplus}$, Marco Unterhofer ${ }^{1}$, Rafael A. Rojas ${ }^{1, *}$, , Luca Gualtieri ${ }^{1}$, \\ Manuel Woschank ${ }^{2}\left(\right.$ D) and Dominik T. Matt ${ }^{1,3}$ (D) \\ 1 Industrial Engineering and Automation (IEA), Faculty of Science and Technology, Free University of \\ Bozen-Bolzano, 39100 Bolzano, Italy; erwin.rauch@unibz.it (E.R.); marco.unterhofer@unibz.it (M.U.); \\ luca.gualtieri@unibz.it (L.G.); dominik.matt@unibz.it (D.T.M.) \\ 2 Chair of Industrial Logistics, Monanuniversitaet Leoben, 8700 Leoben, Austria; \\ manuel.woschank@unileoben.ac.at \\ 3 Innovation Engineering Center (IEC), Fraunhofer Italia Research s.c.a.r.l., 39100 Bolzano, Italy \\ * Correspondence: rafael.rojas@unibz.it
}

Received: 30 March 2020; Accepted: 22 April 2020; Published: 27 April 2020

\begin{abstract}
Industry 4.0 has attracted the attention of manufacturing companies over the past ten years. Despite efforts in research and knowledge transfer from research to practice, the introduction of Industry 4.0 concepts and technologies is still a major challenge for many companies, especially small and medium-sized enterprises (SMEs). Many of these SMEs have no overview of existing Industry 4.0 concepts and technologies, how they are implemented in their own companies, and which concepts and technologies should primarily be focused on future Industry 4.0 implementation measures. The aim of this research was to develop an assessment model for SMEs that is easy to apply, provides a clear overview of existing Industry 4.0 concepts, and supports SMEs in defining their individual strategy to introduce Industry 4.0 in their firm. The maturity level-based assessment tool presented in this work includes a catalog of 42 Industry 4.0 concepts and a norm strategy based on the results of the assessment to support SMEs in introducing the most promising concepts. For testing and validation purposes, the assessment model has been applied in a field study with 17 industrial companies.
\end{abstract}

Keywords: industry 4.0; small and medium-sized enterprises; SME; assessment model; sustainability

\section{Introduction}

The proclamation of the fourth industrial revolution with the aim of a digital transformation of companies changed the industrial world. While in the past a focus was given to the introduction of lean production [1,2], almost every modern enterprise aspired in recent years to become a proper smart factory according to the 'Industry 4.0' principles. In the industrial environment, a curious feeling grew. At first glance, Industry 4.0 was not really perceived as an opportunity, but more as a challenge. Since the first use of the term Industry 4.0 in 2011 [3], many studies have been conducted to investigate the impact of Industry 4.0, its significance for the sustainable competitiveness of companies, the related technologies, as well as methods and strategies for the introduction and implementation of Industry 4.0 in industrial enterprises.

Industry 4.0 is considered to be another word for the fourth industrial revolution [3]. After mechanization, electrification, and computerization, the fourth stage of industrialization aims to introduce concepts like cyber-physical systems (CPS), internet of things (IoT), automation, human-machine interaction (HMI), as well as advanced manufacturing technologies in an intelligent and digitalized factory environment [4]. A distinctive feature of the fourth industrial revolution is 
the ability to combine the digital and the physical world, affecting a broad spectrum of industrial disciplines [5]. The term was introduced in 2011 by a German group of scientists during the Hannover Fair event, which symbolized the beginning of this fourth industrial revolution [6]. Since then, the term Industry 4.0, or also its synonym smart manufacturing [7], has been one of the most popular manufacturing topics among industry and academia in the world $[3,8,9]$.

Considering recent developments in terms of the industrial progression to smart factories and the fourth industrial revolution, companies are overwhelmed and seem to be incapable of developing appropriate implementation strategies [10]. Each company has to analyze its situation and its individual needs and then choose those Industry 4.0 concepts that promise the best prospects for achieving the goals set [11]. There is a need to develop suitable models and instruments to assess the current status or maturity of applied technologies in industrial companies and to implement Industry 4.0 concepts based on the appropriateness for the individual company.

One of the remarkable works, titled 'Guideline Industry 4.0-Guiding principles for the implementation of Industry 4.0 in small and medium-sized businesses', presented by the VDMA (German Engineering Federation), proposes an 'Industry 4.0-toolbox' that should provide first guidance in the challenging change process [12]. The supplied toolbox was perceived as an acceptable starting base to assess one's own company regarding the implementation of Industry 4.0 technologies and concepts, but is limited to the evaluation of a few concepts for product design and manufacturing.

The need for instruments for the assessment of one's own company regarding the level of Industry 4.0 implementation motivated researchers to develop further models. Schumacher et al. [13] developed an assessment model for the determination of the readiness for Industry 4.0-related measures. Compared with former works [14], the degree of completeness of the model is enhanced through the inclusion and combination of technological and organizational aspects, which are categorized into nine dimensions and single specific assessment items.

However, there is still room for further improvements in the development of models for the evaluation of companies introducing Industry 4.0. Therefore this work aimed to enrich the evolution of Industry 4.0 assessment models giving a specific focus to small and medium-sized enterprises. Further, it opens doors to new and enriched evaluation possibilities that are no longer addressing a problem of readiness of enterprises, but one affiliated to the maturity level associated to the Industry 4.0 implementation. Small and medium-sized enterprises (SMEs) are usually less informed about Industry 4.0 concepts. Therefore, an assessment model must clearly describe the concepts and also show the companies which different possibilities of concepts and technologies Industry 4.0 has to offer. Subsequently, such a model should support SMEs simply and pragmatically to show their status of implementation and the potential for future Industry 4.0 projects. Thus, the model's objective was (i) to inform SMEs about the existing Industry 4.0 concepts, (ii) to assess the current progress in the implementation and application of these concepts, and (iii) to signalize to SMEs which of the Industry 4.0 concepts are the most important ones for the individual company.

The paper is structured as follows: after a first introduction to the topic in Section 1, the authors provide in Section 2 the research methodology for this work. Section 3 follows a literature review of existing assessment and maturity models, as well as for the identification of Industry 4.0 concepts and technologies. Section 4 provides a detailed insight into the structure and development of the proposed maturity level-based assessment tool. Section 5 describes the evaluation and testing of the developed model in several industrial companies. Section 6 provides a discussion about the proposed model, the implications for practitioners, as well as its limitations. Finally, the paper ends with a summary and a look at further research needed in the future.

\section{Research Methodology}

In this work, we applied a research approach in three phases (see also Figure 1): (i) in the first phase a literature review was conducted in 2018 and Industry 4.0 concepts and technologies were identified; (ii) in the second phase the assessment tool for SMEs was developed in 2018-2019; (iii) in 
the third phase the developed assessment model was tested and validated by using a field study with industrial companies in 2019.

In the first phase (see also Section 3), we conducted a literature review to analyze already existing assessment models and their suitability for SMEs. In addition, we looked into the scientific literature for Industry 4.0 concepts and technologies to assess their implementation in SMEs in the assessment model.

In the second phase (see also Section 4), we developed the maturity level-based assessment tool for Industry 4.0 to be used in SMEs. In the first step, we defined the maturity levels for each of the Industry 4.0 concepts and technologies. The assessment model foresees the evaluation of the current implementation of Industry 4.0 in SMEs as well as the future target implementation. The difference between current and target state defines the gap that needs to be overcome by SMEs. Further, the assessment model should include also the assessment of the potential of each concept/technology for the single SME. Based on the gap and the potential of Industry 4.0 concepts/technologies, a norm strategy matrix indicates to SMEs a meaningful prioritization of final implementation measures.

In the third phase (see also Section 5), we conducted a field study with 17 industrial companies from Italy, Austria, Slovakia, and the United States to test and validate the developed assessment model. First, we will describe the structure of the field study describing the dimensions of the analyzed companies, their origin, as well as the approach of the field study. Then we present the results of the field study for the application of the assessment model and discuss the lessons learned to focus on feedback from SMEs.
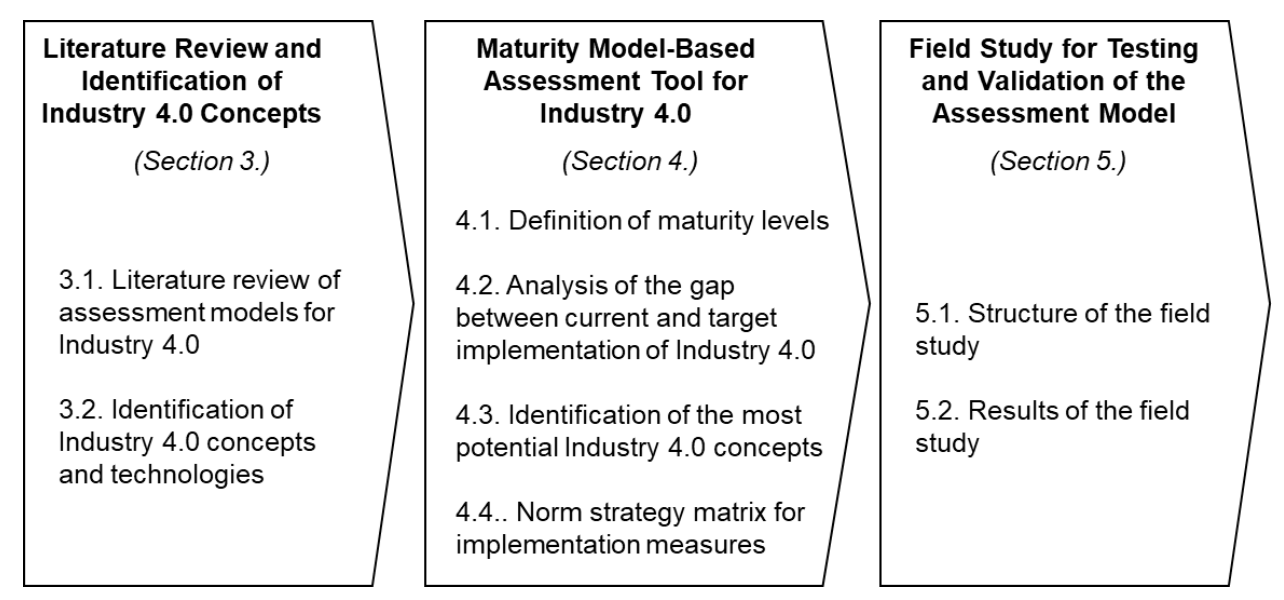

Figure 1. Research methodology used in this work.

\section{Literature Review and Identification of Industry 4.0 Concepts and Technologies}

\subsection{Overview of Existing Assessment and Maturity Models for SMEs}

The analysis of existing assessment and/or maturity models for Industry 4.0 was based on a literature search in SCOPUS database, as this is one of the leading and most complete scientific databases for industrial and manufacturing engineering. The research team used for the literature analysis the following research query: (TITLE-ABS-KEY ("Industry 4.0") AND TITLE-ABS-KEY (assessment OR maturity) AND TITLE-ABS-KEY (sme OR "small and medium sized")) AND (LIMIT TO (LANGUAGE,"English")), with an output of 32 search hits. In the search, only works in the English language were considered, excluding 1 work in German. The remaining 31 works were published mainly as conference papers ( 22 works) and conference reviews ( 2 works), while 7 works were articles/reviews in journals and 1 had been published as a book chapter. This shows that the development of assessment models for Industry 4.0 in SMEs is a quite new topic and is already mainly discussed in scientific conferences and not yet so much in peer-reviewed journals. Also, the year of publication confirmed this as 2 works were published in 2016, 14 works in 2018 and 16 works in 2019. In the first screening of title and abstract, a total of 19 works were encoded as firmly pertinent. In a 
second screening reading all remaining works, a total of 13 research papers were considered for a further content analysis.

In the following, a summary of the content analysis of the remaining works (see Table 1) will be given to explain the current status of assessment and maturity models with a special focus on SMEs.

The first group of works focused on maturity-based assessment models determining the maturity/implementation of concepts and technologies from Industry 4.0. The authors in [15] were focused more on the maturity levels of the general implementation of an Industry 4.0 strategy but did not go into detail regarding single Industry 4.0 concepts. The model in [16] was based on five maturity levels (novice, beginner, learner, intermediate, expert) as well as five dimensions (finance, people, strategy, process, product). Also in this model, the assessment provided only a rough overview of seven categories of Industry 4.0 so-called toolboxes (manufacturing/fabrication, design and simulation, robotics and automation, sensors and connectivity, cloud/storage, data analytics, and business management), but not of the single Industry 4.0 concepts and technologies. The authors in [17] presented a study of the maturity of Industry 4.0 in German companies, focusing on six dimensions (product development process, steering, and control, manufacturing and operation, smart services, process organization, big data). The authors in [18] presented a maturity level assessment with five fields of action and 29 subordinated action elements. The action elements showed only areas of implementation (e.g., production logistics or communication), thus the results gave only an overview of a general assumption of the implementation of Industry 4.0 in each action element, but not based on single Industry 4.0 concepts and technologies. In [19] the authors proposed a maturity model based on five dimensions (strategy, technology, production, products, people) and a Likert scale from 1 to 5 . The study used a Likert scale from 0 to 6. In [20] the authors used five dimensions (strategy, people, processes, technology integration) with a Likert scale from 1 to 5 . Also in the latter cases, the maturity assessment did not go in deep on the concept and technology level, but instead remained on a very superficial level of exploration.

The second group of works concentrated on the assessment model for evaluating the level of readiness of Industry 4.0. [21] determined the readiness for Industry 4.0 based on six dimensions (1-strategy and organization; 2-smart factory; 3-smart products; 4 -data-driven services; 5-smart operations; 6-employees) based on a Likert scale from 0 to 5 . The works did not provide any further insight into the readiness regarding detailed Industry 4.0 concepts. The work described in [22] presented a readiness self-assessment for craftsmanship companies with the three dimensions production/operations, digitalization, and ecosystem. In these three dimensions, a total of 23 items (e.g., data security, perception of digitalization, quality of internet connection) were assessed with a Likert scale from 1 to 5 . Also, in [23] the model provided only a rough overview of two dimensions (smart factory, strategy, and culture). The authors in [24] provided a readiness assessment based on five dimensions (manufacturing and operations, people capability, technology-driven process, digital support, and business and organization strategy) and 43 subdimensions with a Likert scale from 0 to 4 . Summarizing, most of the models discussed did not go very in depth and followed a different scope to the one in this work as they assessed the readiness for Industry 4.0 and not the maturity of applied Industry 4.0 concepts and technologies.

The third group of works dealt with a specific assessment model for Industry 4.0 in SMEs. In [25] the following process modules of intralogistics were assessed: incoming goods, internal transport, storage, order picking, packaging, and outgoing goods. In [26], four dimensions (data, communication, processes, and intellectual capital) were assessed based on a Likert scale from 1 to 5 . A characteristic of this work was that each maturity level was described in detail with examples, which makes it easier for SMEs to validate the right maturity level. The work in [27] referred to nine characteristics of SMEs (e.g., ability to produce customized products) and assessed the maturity of lean and Industry 4.0 components). In summary, this group of assessment models dealt only with specific areas of an SME, like logistics, or with additional concepts from lean manufacturing and is therefore not suitable for the scope of the work proposed in this article. 
Table 1. Overview of existing assessment and maturity models for small and medium-sized enterprises (SMEs).

\begin{tabular}{|c|c|c|c|c|c|}
\hline No & Ref. & Authors & Year & Title & Assessment of \\
\hline 1 & [15] & Ganzarain J., Errasti N. & 2016 & Three-stage maturity model in SMEs towards industry 4.0 & maturity \\
\hline 2 & [16] & Mittal S., Romero D., Wuest T. & 2018 & Towards a smart manufacturing maturity model for SMEs (SM3E) & maturity \\
\hline 3 & [17] & $\begin{array}{l}\text { Bittighofer D., Dust M., Irslinger A., } \\
\text { Liebich M., Martin L. }\end{array}$ & 2018 & State of Industry 4.0 Across German Companies & maturity \\
\hline 4 & [18] & Puchan J., Zeifang A., Leu J.-D. & 2019 & Industry 4.0 in Practice-Identification of Industry 4.0 Success Patterns & maturity \\
\hline 5 & [19] & Trotta D., Garengo P. & 2019 & Assessing Industry 4.0 Maturity: An Essential Scale for SMEs & maturity \\
\hline 6 & [20] & Pirola F., Cimini C., Pinto R. & 2019 & Digital readiness assessment of Italian SMEs: a case-study research & maturity \\
\hline 7 & [21] & $\begin{array}{l}\text { Hamidi S.R., Aziz A.A., Shuhidan S.M., } \\
\text { Aziz A.A., Mokhsin M. }\end{array}$ & 2018 & SMEs maturity model assessment of IR4.0 digital transformation & readiness \\
\hline 8 & [22] & Sheen D.-P., Yang Y. & 2018 & Assessment of Readiness for Smart Manufacturing and Innovation in Korea & readiness \\
\hline 9 & [23] & Chonsawat N., Sopadang A. & 2019 & The development of the maturity model to evaluate the smart SMEs 4.0 readiness & readiness \\
\hline 10 & [24] & $\begin{array}{l}\text { Brozzi R., D'Amico R.D., Pasetti Monizza } \\
\text { G., Marcher C., Riedl M., Matt D. }\end{array}$ & 2018 & $\begin{array}{l}\text { Design of self-assessment tools to measure industry } 4.0 \text { readiness. A methodological } \\
\text { approach for craftsmanship SMEs }\end{array}$ & readiness \\
\hline 11 & [25] & Schiffer M., Wiendahl H.-H., Saretz B. & 2019 & Self-assessment of Industry 4.0 Technologies in Intralogistics for SME's & specific \\
\hline 12 & [26] & Krowas K., Riedel R. & 2019 & Planning Guideline and Maturity Model for Intra-logistics 4.0 in SME & specific \\
\hline 13 & [27] & Kolla S., Minufekr M., Plapper P. & 2019 & $\begin{array}{l}\text { Deriving essential components of lean and industry } 4.0 \text { assessment model for } \\
\text { manufacturing SMEs }\end{array}$ & specific \\
\hline
\end{tabular}


Most of the authors used a Likert scale from 1 to 5 for measuring the maturity of Industry 4.0, which was applied also in our work. All works did not go into detail about the single Industry 4.0 concepts and technologies and evaluated only dimensions or fields of application. As one of the most difficult tasks for SMEs is to understand what kind of concepts belong to Industry 4.0, we maintained it was important to develop a much more detailed assessment model. The evaluation might be difficult for SMEs if only a Likert scale with a vague description is shown (e.g., from beginner to expert). We used here the procedure as shown in [26], where each maturity level is well described with examples to simplify the use of the assessment model for SMEs. Further, in all the shown approaches, an evaluation to assess also a target maturity level for SMEs was missing. Not all SMEs need the maximum level of Industry 4.0 for their purposes, thus the maximum maturity level should not be seen as something that must be attained at all costs. In addition, the analyzed assessment models do not show any procedure to rank the potential implementation steps or technologies for a single company. All these points should be included in the new proposed assessment model.

\subsection{Identification of Industry 4.0 Concepts and Technologies}

To design an assessment model for maturity in the application of Industry 4.0 technologies and concepts, the assessment units must first be identified and defined. As mentioned before in Section 3.1, the aim is to provide a comprehensive method catalog with Industry 4.0 concepts and technologies to support SMEs in the selection of measures to be implemented. Therefore, the research team carried out a systematic literature analysis with the keyword "Industry 4.0 " in the database SCOPUS in the first year of the research project. From initially 733 works a large number of publications were excluded based on exclusion criteria like type of paper (only journal articles, reviews, and articles in press were considered), the cover period (from 2011 to 2017), the language (only works in English), the subject area (only papers belonging to engineering, computer science, business, materials science, social sciences, decision sciences, management and accounting, energy, econometrics and finance, multidisciplinary, economics and psychology were considered in the search) were analyzed. The remaining 102 works were screened by three independent researchers to guarantee objectivity in the analysis. The screening process resulted in a total of 27 publications that were defined as firmly pertinent for further analysis, which means that they provided clear information about Industry 4.0 technologies and concepts.

These identified works formed the basis for a subsequent content analysis, from which Industry 4.0 concepts and technologies could be extracted. The content analysis resulted in a first step in 75 Industry 4.0 topics that were condensed by the research team into 42 meaningful Industry 4.0 concepts and technologies used as a basis for the proposed assessment model. The reason for the adopted consolidation lay in the fact that many of the identified Industry 4.0 topics were characterized by a subject or industry-specific nature with the need for generalization.

The broad spectrum of the identified Industry 4.0 concepts and technologies required structuring into several levels of Industry 4.0 dimensions (see also Table 2). In the first dimension level the concepts were classified as follows:

- Operations (concepts/technologies for production and operational processes)

- Organization (concepts/technologies for organizational and management-oriented processes)

- Socio-Culture (concepts/technologies related to corporate culture and employee-related topics)

- Technology (data and process-driven technologies).

In the second dimension level, a total of 21 subdimensions were identified. Table 2 summarizes the identified Industry 4.0 concepts and technologies, including dimension level I and II in alphabetical order. 
Table 2. Identified and generalized Industry 4.0 concepts and technologies.

\begin{tabular}{|c|c|c|c|}
\hline No & Dimension Level I & Dimension Level II & Industry 4.0 Concepts and Technologies \\
\hline 1 & \multirow{9}{*}{ Operations } & & Agile Manufacturing System \\
\hline 2 & & & Self-Adapting Manufacturing Systems \\
\hline 3 & & Agile Manufacturing Systems & Continuous and Uninterrupted Material Flow Models \\
\hline 4 & & & Plug and Produce \\
\hline 5 & & & Decision Support Systems \\
\hline 6 & & Monitoring \& Decision Systems & Integrated and Digital Real-Time Monitoring Systems \\
\hline 7 & & & Remote Monitoring of Products \\
\hline 8 & & Big Data & Big Data Analytics \\
\hline 9 & & Production Planning and Control & Enterprise Resource Planning / Manufacturing Execution System \\
\hline 10 & \multirow{10}{*}{ Organization } & & Digital Product-Service Systems \\
\hline 11 & & & Servitization and Sharing Economy \\
\hline 12 & & & Digital Add-on or Upgrade \\
\hline 13 & & Business Model 4.0 & Digital Lock-In \\
\hline 14 & & & Freemium \\
\hline 15 & & & Digital Point of Sales \\
\hline 16 & & Innovation strategy & Open Innovation \\
\hline 17 & & Strategy 4.0 & Industry 4.0 Roadmap \\
\hline 18 & & Supply Chain Management 4.0 & Sustainable Supply Chain Design \\
\hline 19 & & Supply Chain Management 4.0 & Collaboration Network Models \\
\hline 20 & \multirow{4}{*}{ Socio-Culture } & Human Resource 4.0 & Training 4.0 \\
\hline 21 & & Work 4.0 & Role of the Operator \\
\hline 22 & & Culture 4.0 & Cultural Transformation \\
\hline 23 & & Big Data & Cloud Computing \\
\hline 24 & \multirow{19}{*}{ Technology } & & Digital and Connected Workstations \\
\hline 25 & & Communication \& Connectivity & E-Kanban \\
\hline 26 & & & IoT and Cyber-Physical Systems \\
\hline 27 & & Cyber Security & Cyber Security \\
\hline 28 & & Deep Learning, Machine Learning, Artificial & Artificial Intelligence \\
\hline 29 & & Intelligence & Object Self Service \\
\hline 30 & & Identification and Tracking Technology & Identification and Tracking Technology \\
\hline 31 & & Additive Manufacturing & Additive Manufacturing (3D Printing) \\
\hline 32 & & & Predictive Maintenance \\
\hline 33 & & Maintenance & Telemaintenance \\
\hline 34 & & & Automated Storage Systems \\
\hline 35 & & & Automated Transport Systems \\
\hline 36 & & Robotics \& Automation & Automated Manufacturing/Assembly \\
\hline 37 & & & Collaborative Robotics \\
\hline 38 & & & Smart Assistance Systems \\
\hline 39 & & Product Design and Development & Product Data Management and Product Lifecycle Management \\
\hline 40 & & Standards 4.0 & Cyber-Physical System Standards \\
\hline 41 & & Virtual Reality, Augmented Reality, and Simulation & Virtual and Augmented Reality \\
\hline 42 & & Virtual Reality, Augmented Reality, and Simulation & Simulation \\
\hline
\end{tabular}




\section{Maturity Level-Based Assessment Tool of Industry 4.0 for SMEs}

\subsection{Maturity Levels Used in the Assessment Model}

First of all, SMEs have to insert in the assessment model their general data, like operating sector, number of employees, annual revenue, and balance sheet total. These data are used in a later stage to compare their own results with the average of other SMEs of the same size and the same sector. In the next step, SMEs have to define the maturity level of the identified Industry 4.0 concepts and technologies (see Section 3.2) in their own company. As already seen in Section 3.1, many assessment models use such maturity levels to express the progress of implementation of Industry 4.0 in their own company. We wanted to apply the same approach also in our assessment model for Industry 4.0 in SMEs. Each level should specify the peculiarities and the progress of the evaluated enterprises or desires to achieve to become a smart enterprise.

As already mentioned in Section 3.1, we wanted to adopt also a Likert scale with five maturity levels. According to the results of the review of maturity level-based assessment models, it can be confirmed that five stages are most common and suitable to map the implementation or maturity of Industry 4.0 concepts. To facilitate the application of the assessment model in SMEs, the maturity levels are expressed and described not only by numbers from 1 to 5 but with a combination of a single term and a brief statement/example. First, tests with an SME have shown that persons asked to do the assessment based only on a Likert scale from 1 to 5 (therefore described only by numbers) have difficulties deciding which is the right value for the stage of implementation in their company as for many Industry 4.0 concepts they have no experience with what could be the lowest stage or the highest stage of implementation. Next, tests that added a term to the numbers facilitated the assessment, but still caused uncertainty (and therefore a lower quality of the assessment data) due to many new and innovative Industry 4.0 concepts where people needed some more explanation and, if possible, also an example. The explained maturity levels are illustrated in Figure 2 as follows.

\begin{tabular}{|c|c|c|c|c|c|}
\hline $\begin{array}{l}\text { INDUSTRY } 4.0 \\
\text { CONCEPT }\end{array}$ & Maturity Level 1 & Maturity Level 2 & Maturity Level 3 & Maturity Level 4 & Maturity Level 5 \\
\hline $\begin{array}{l}\text { Remote Monitoring of } \\
\text { Products }\end{array}$ & $\begin{array}{l}\text { Products Are Not } \\
\text { Monitored } \\
\text { /products are not monitored } \\
\text { after delivery }\end{array}$ & $\begin{array}{l}\text { Spotwise Product Checks } \\
\text { /products are monitored } \\
\text { spotwise by the customer or } \\
\text { a sales agent or a technician }\end{array}$ & $\begin{array}{l}\text { Periodic Product Checks } \\
\text { /products are monitored by } \\
\text { the manufacturer through } \\
\text { periodic condition checks }\end{array}$ & $\begin{array}{l}\text { Remote Product } \\
\text { Monitoring } \\
\text { /products are digitally } \\
\text { monitored by the } \\
\text { manufacturer through } \\
\text { remote access }\end{array}$ & $\begin{array}{l}\text { Remote Product Control } \\
\text { /products are monitored and } \\
\text { controlled through remote } \\
\text { access }\end{array}$ \\
\hline Big Data Analytics & $\begin{array}{l}\text { No Data Analytics } \\
\text { /no use of existing data }\end{array}$ & $\begin{array}{l}\text { Manual Data Analytics of } \\
\text { Existing Data } \\
\text { /minimal use of existing data } \\
\text { based on Excel or similar }\end{array}$ & $\begin{array}{l}\text { Big Data Projects } \\
\text { /collect data in a structured } \\
\text { way and perform big data } \\
\text { analytics projects through } \\
\text { external experts }\end{array}$ & $\begin{array}{l}\text { Big Data Analytics Tools } \\
\text { /collect and analyze } \\
\text { production and logistics data } \\
\text { for process optimization } \\
\text { with big data analytics tools }\end{array}$ & $\begin{array}{l}\text { Internal Big Data } \\
\text { Analytics Experts } \\
\text { /professional application of } \\
\text { big data analytics through } \\
\text { skilled internal experts } \\
\text { (production data analysts) }\end{array}$ \\
\hline ERP/MES & No ERP system & $\begin{array}{l}\text { ERP System } \\
\text { /ERP system implemented }\end{array}$ & $\begin{array}{l}\text { ERP and PPC System } \\
\text { /production Planning and } \\
\text { Control system used for } \\
\text { material requirement } \\
\text { planning }\end{array}$ & $\begin{array}{l}\text { MES Implementation } \\
\text { /MES system or similar } \\
\text { implemented but not } \\
\text { integrated with ERP }\end{array}$ & $\begin{array}{l}\text { ERP/MES Integration } \\
\text { /ERP and MES are } \\
\text { integrated and communicate } \\
\text { with each other }\end{array}$ \\
\hline $\begin{array}{l}\text { Digital Product-Service } \\
\text { Systems }\end{array}$ & Only Physical Product & $\begin{array}{l}\text { Maintenance Business } \\
\text { Models } \\
\text { /maintenance services sold } \\
\text { together with product }\end{array}$ & $\begin{array}{l}\text { Product-Service System } \\
\text { /extended services sold } \\
\text { together with product }\end{array}$ & $\begin{array}{l}\text { Digital Product-Service } \\
\text { Systems } \\
\text { /digital services sold } \\
\text { together with the product }\end{array}$ & $\begin{array}{l}\text { Web/Cloud-based } \\
\text { Product-Service } \\
\text { Architectures } \\
\text { /digital services available on } \\
\text { via web, app or doud }\end{array}$ \\
\hline $\begin{array}{l}\text { Servitization and Sharing } \\
\text { Economy }\end{array}$ & $\begin{array}{l}\text { Ownership Based } \\
\text { Business Model } \\
\text { /customer buys physical } \\
\text { product (Ownership) }\end{array}$ & $\begin{array}{l}\text { Leasing Based Business } \\
\text { Model } \\
\text { /customer pays the leasing } \\
\text { rate to get ownership }\end{array}$ & $\begin{array}{l}\text { Rental Based Business } \\
\text { Model } \\
\text { /customer pays a rental rate } \\
\text { (no ownership intended) }\end{array}$ & $\begin{array}{l}\text { Servitization Model } \\
\text { /customer pays for the } \\
\text { service }\end{array}$ & $\begin{array}{l}\text { Sharing Economy } \\
\text { Platform Model } \\
\\
\text { /customers share access to } \\
\text { products or services with } \\
\text { other customers }\end{array}$ \\
\hline
\end{tabular}

Figure 2. Exemplary representation of maturity levels of Industry 4.0 concepts.

\subsection{Analysis of the Current Status of Implementation and the Target Status}

The company completes the assessment of the current status regarding the implementation of Industry 4.0 concepts by selecting one of the maturity levels shown above. In our assessment model, this maturity level is called the 'firm's I4.0 score'. In addition, the company also indicates a degree of 
maturity that it would like to achieve in the medium term, and where the firm also realistically sees the feasibility of implementation. This objective of a future maturity level is called the 'target level'.

These two values are the basis for the calculation of the 'I4.0 gap' that describes the difference between target level and the firm's I4.0 score. This gap should act as a measure of the difficulty for the SME to achieve the future target level of Industry 4.0 for each single Industry 4.0 concept.

Figure 3 shows a screenshot of the MS Excel-based maturity level-based assessment tool with the fields to be filled in by the SME to determine the firm's I4.0 score and the target level. For the development of a prototype of the assessment model, MS Excel was chosen as it is widely spread in SMEs and easy to use also for nonexpert users of MS Excel. In the final stage of the project a web-based self-assessment model is developed to maximize dissemination.

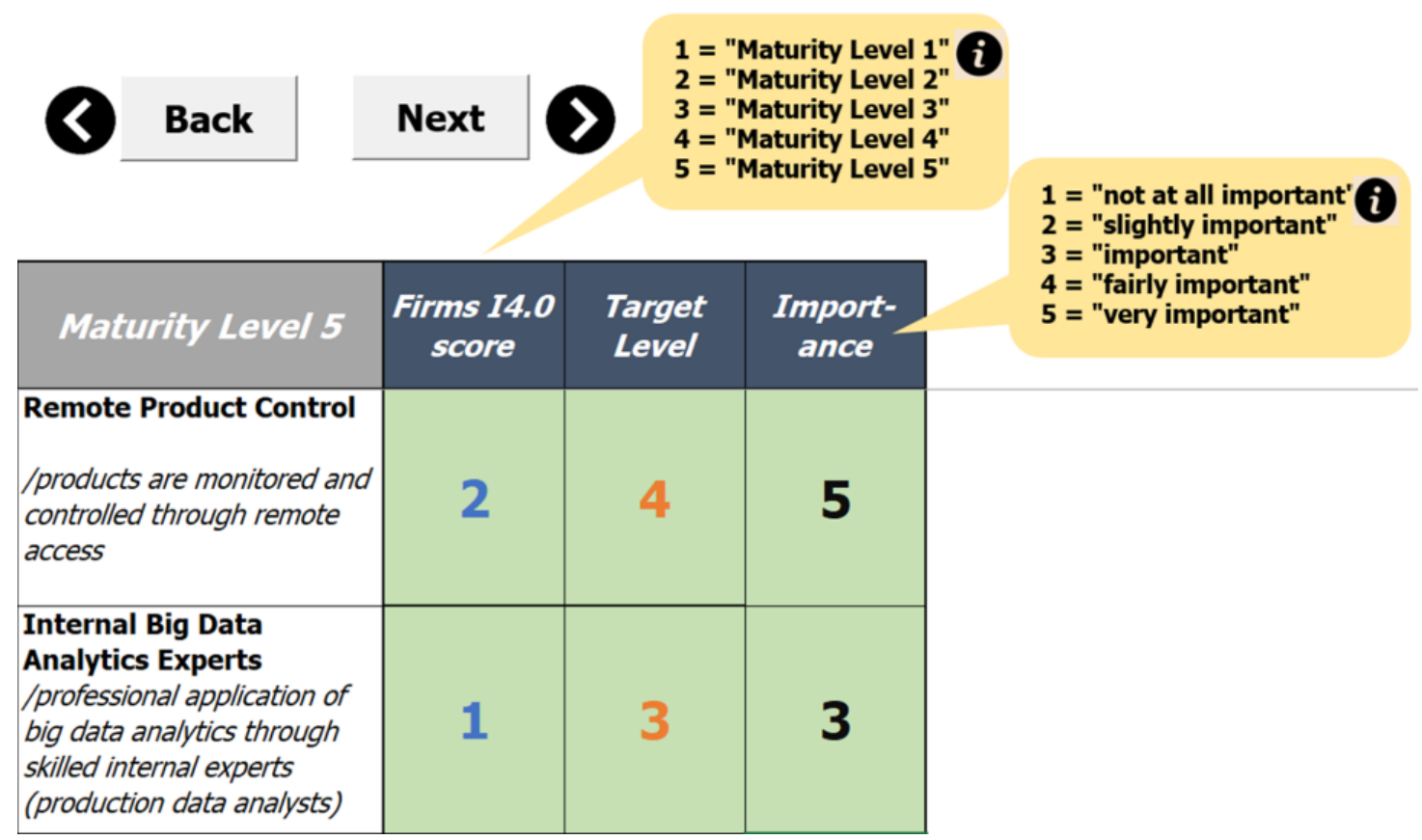

Figure 3. Fields to be filled in for firm's I4.0 score, target level, and the importance of each Industry 4.0 concept.

Figure 4 shows an example of the visualization of the firm's I4.0 score and the target level automatically generated by the MS Excel prototype of the assessment model. The representation in the radar chart is intended to simplify the evaluation of the assessment for SMEs, as the gap between today and tomorrow is directly visible.

The radar charts illustrate the firm's Industry 4.0 score as well as the firm's target score for each Industry 4.0 concept categorized in an operational I4.0 level, an organizational I4.0 level, a social-cultural I4.0 level, as well as a technological I4.0 level (further subdivided into data-driven and process-driven technological level).

In the visual representation of the results, the technology-related Industry 4.0 concepts are subdivided into a group of data-driven technologies and process-driven technologies (see Table 3). 
Table 3. Data-driven and process-driven technologies.

\begin{tabular}{cc}
\hline Data-driven Technologies & Process-driven Technologies \\
\hline Cloud Computing & Additive Manufacturing (3D-Printing) \\
Digital and Connected Workstations & Predictive Maintenance \\
E-Kanban & Telemaintenance \\
Internet of Things and Cyber-Physical & Automated Storage Systems \\
Cybems & Automated Transport Systems \\
Artificial Intelligence & Automated Manufacturing \& Assembly \\
Object Self Service & Collaborative Robotics \\
& Smart Assistance Systems \\
Identification and Tracking Technology & Product Data Management and Product Lifecycle Management \\
& Cyber-Physical Systems Standards \\
& Virtual and Augmented Reality \\
& Simulation \\
\hline
\end{tabular}

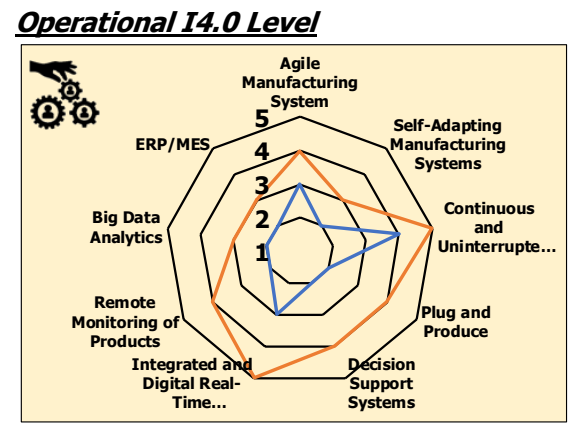

Technological 14.0 Level (data-driven)

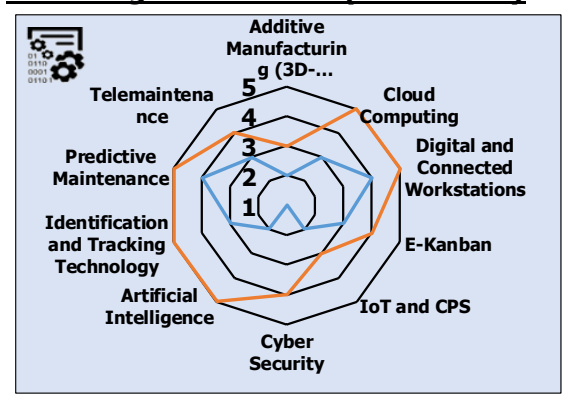

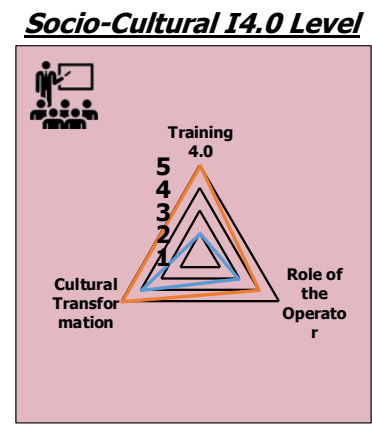

Technological 14.0 Level (process-driven)

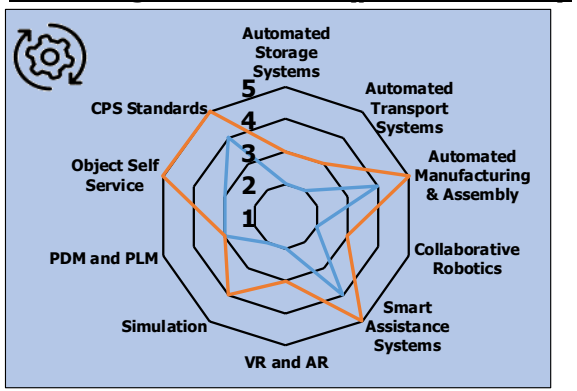

$\odot$ Legend: Firms I4.0 score Firms Target Level

Figure 4. Exemplary visualization of the gap between firm's I4.0 score and the target level.

\subsection{Identification and Ranking of Industry 4.0 Concepts and Technologies with the Highest Potential} in Implementation

In the next step, the company is asked to provide an assessment of the potential ('importance') of the respective Industry 4.0 concept (see also Figure 3). Also, this evaluation is based on a 5-step Likert scale and is meaningful according to the authors, because not every Industry 4.0 concept might be important for the individual company. While for example, the traceability of products is essential and of the highest importance for certain companies and industries (e.g., automotive sector, food sector), this concept will play a much less important role in many other SMEs.

In this respect, the estimation of the importance is used to express the potential of each Industry 4.0 concept for the individual SME. To prioritize the Industry 4.0 concepts and thus to define the basis for implementation measures, the assessment tool automatically generates a ranking based on the identified potential (see Figure 5). 


\begin{tabular}{|c|c|c|}
\hline Rank & I4.0 Concept & I4.0 Potential \\
\hline 1 & Agile Manufacturing System & 5 \\
\hline 2 & Plug and Produce & 5 \\
\hline 3 & Remote Monitoring of Products & 5 \\
\hline 4 & Digital Product-Service Systems & 5 \\
\hline 5 & Industry 4.0 Roadmap & 5 \\
\hline 6 & Training 4.0 & 5 \\
\hline 7 & Additive Manufacturing (3D-Printing) & 5 \\
\hline 8 & $\begin{array}{l}\text { Identification and Tracking } \\
\text { Technology }\end{array}$ & 5 \\
\hline 9 & ERP/MES & 4 \\
\hline 10 & Digital Add-On or Upgrade & 4 \\
\hline
\end{tabular}

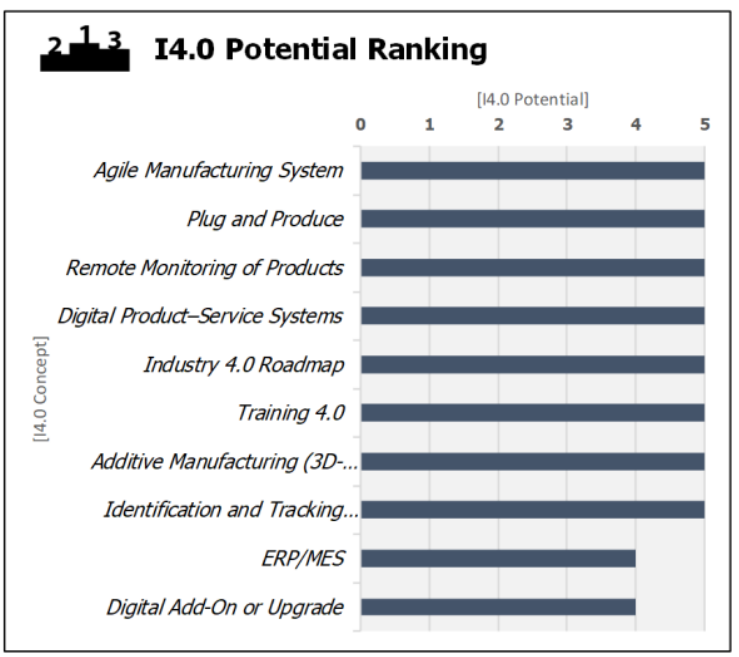

Figure 5. Exemplary visualization of the potential for each Industry 4.0 concept.

\subsection{Norm Strategy Matrix for Defining Implementation Measures}

Not all of the 42 Industry 4.0 concepts listed will be of high potential and not all of them require the same amount of effort and time for implementation. Therefore it makes sense, especially for SMEs with financial and personnel limits, to strive for a gradual implementation of the Industry 4.0 concepts. Both criteria, namely the gap and the identified potential, are therefore combined in a norm strategy matrix as shown in Figure 6, to facilitate the selection and scheduling of implementation measures for Industry 4.0 in terms of time (short-term vs. medium-term implementable I4.0 concepts). Figure 6 shows the matrix schematically with the following standardization strategies depending on the respective quadrant in the diagram:

- Quick Wins (high potential-low gap)

- Must Haves (high potential-high gap)

- Low Hanging Fruits (low potential-low gap)

- Money Pits (low potential-high gap).

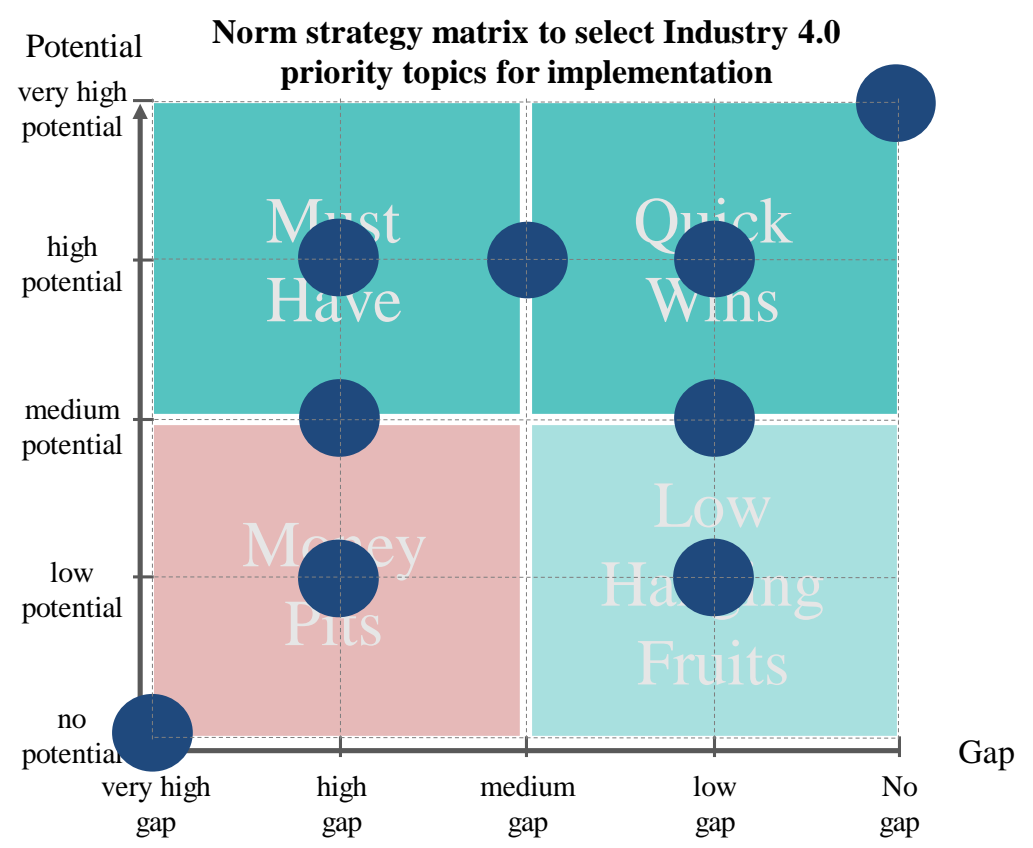

Figure 6. Norm strategy matrix to facilitate the selection and definition of Industry 4.0 measures/projects. 
Depending on the position of the Industry 4.0 concepts, the SMEs can then define whether, and to what extent and in what time frame, implementation measures have to be defined.

\section{Validation of the Industry 4.0 Assessment in a Field Study with SMEs}

\subsection{Structure and Procedure of the Field Study}

A number of 17 SME companies operating in different industrial sectors from Italy (10), Austria (3), Slovakia (1), and the USA (3) participated in the field study. The participating companies in the field study were mainly operating in industrial goods manufacturing (6), industrial supplies and materials (4), construction (3), food (2), and other industries (2). From these companies, seven were small enterprises with up to 49 employees and 10 were medium-sized enterprises with 50-249 employees. The companies had been collaborating with the research team in the $\mathrm{H} 2020$ research project "SME 4.0-Industry 4.0 for SMEs". In the case study companies, the assessment was completed by the company owner/manager or the head of production. In most of the cases, they called for specific concepts experts from product development, IT department, or other operational departments. To identify difficulties in completing the assessment, a representative of the research team was always present. This was done to monitor the time spent on completing the assessment, to record difficulties in completing the assessment, and then to ask the companies for their feedback on the user-friendliness of the assessment. At no time did the researcher present intervene in the evaluation or influence the participant in the assessment.

All participants assessed the firm's I4.0 score, the target level and the importance of the respective Industry 4.0 concepts for their company. As a result and for their benefit, they learned possible Industry 4.0 concepts and technologies, they got an overview of their status and the gap for each concept, and they received a visual ranking of the most potential concepts for their firm.

\subsection{Results of the Field Study}

In general, the assessed importance/potential of each single Industry 4.0 concept was analyzed in the form of the average value, the respective standard deviation, and the coefficient of variation as a measure of relative variability of the answers as well as the number of answers. This analysis was used by the research team to identify suitable/potential Industry 4.0 concepts from the viewpoint of SMEs. These results are summarized and presented in [28].

In this work, we were more interested in the overall results of the field study and the feedback from the participating persons using the assessment model. Therefore we analyzed the data of the field study to investigate in the first step the maturity level and target level for Industry 4.0 concepts according to the participating SMEs (see Figure 7).

The overall results showed that the current maturity level of Industry 4.0 concepts in SMEs is generally very low. Comparing the single categories and I4.0 concepts depicted in Figure 7 we can see that the 10 concepts with the highest Firms I4.0 score were (from highest to lowest value): (1) agile manufacturing, (2) cloud computing, (3) product data management (PDM) and product lifecycle management (PLM), (4) enterprise resource planning (ERP) and manufacturing execution system (MES), (5) role of the operator, (6) simulation, (7) automation in manufacturing and assembly, (8) integrated and digital real-time monitoring systems, (9) collaboration network models, and (10) self-adapting manufacturing models.

The 10 Industry 4.0 concepts with the highest target level were (from highest to lowest value): (1) integrated and digital real-time monitoring systems, (2) agile manufacturing systems, (3) ERP/MES, (4) Industry 4.0 roadmap, (5) cloud computing, (6) digital and connected workstations, (7) cultural transformation, (8) PDM and PLM, (9) big data analytics, and (10) training 4.0.

Further, it is interesting to know those Industry 4.0 concepts that showed the greatest gap between the current level and the target level (from highest to lowest value): (1) integrated and digital real-time monitoring systems, (2) Industry 4.0 roadmap, (3) Training 4.0, (4) cultural transformation, (5) digital 
and connected workstations, (6) ERP/MES, (7) internet of things and cyber-physical systems, (8) decision support systems, (9) predictive maintenance, and (10) big data analytics.

In the next step, we analyzed the data to determine the average potential of the Industry 4.0 concepts according to the participating SMEs in the field study (see Figure 8).
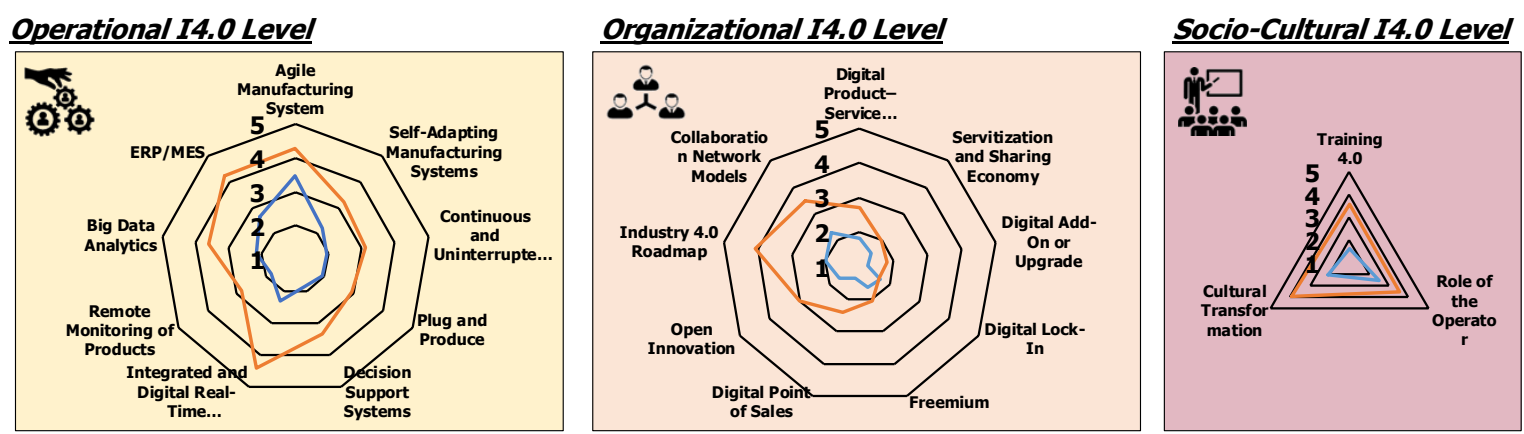

\section{Technological 14.0 Level (data-driven)}
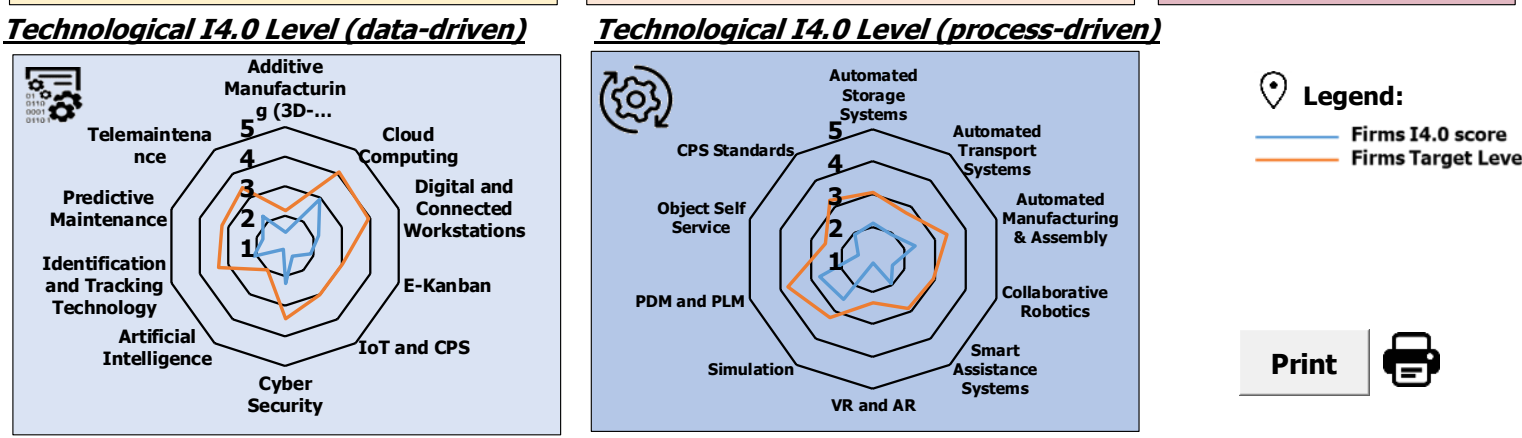

Print

Figure 7. Visualization of average Firms I4.0 Score and Target level of SMEs in the field study.

\begin{tabular}{c|l|c} 
Rank & \multicolumn{1}{|c|}{ I4.0 Concept } & I4.0 Potential \\
\hline 1 & Agile Manufacturing System & 4.24 \\
\hline 2 & Digital and Connected Workstations & 4.24 \\
\hline 3 & $\begin{array}{l}\text { Integrated and Digital Real-Time } \\
\text { Monitoring Systems }\end{array}$ & 4.12 \\
\hline 4 & Industry 4.0 Roadmap & 4.06 \\
\hline 5 & ERP/MES & 4.00 \\
\hline 6 & Cultural Transformation & 3.94 \\
\hline 7 & Cyber Security & 3.76 \\
\hline 8 & Training 4.0 & 3.65 \\
\hline 9 & Role of the Operator & 3.65 \\
\hline 10 & Big Data Analytics & 3.59
\end{tabular}

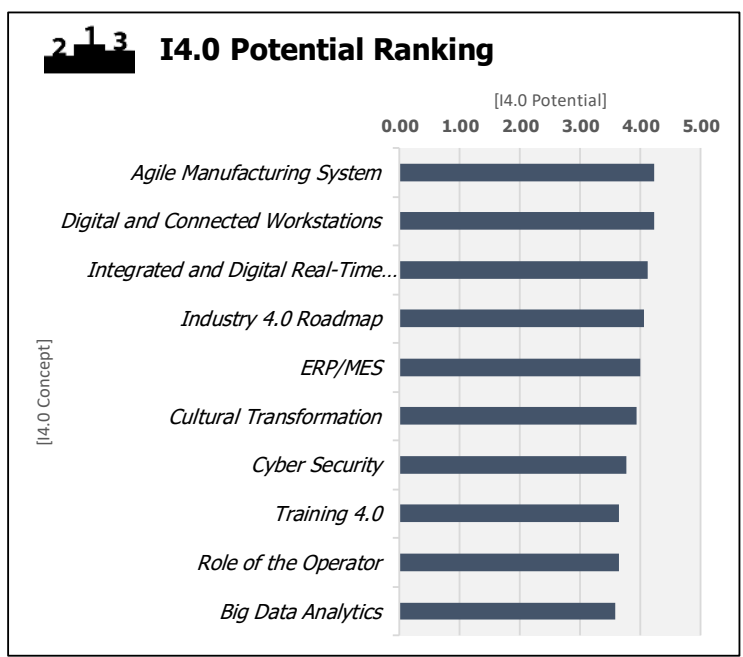

Figure 8. Ranking of the average potential of Industry 4.0 concepts according to SMEs in the field study.

Based on the evaluations of the companies in the field study the most promising Industry 4.0 concepts are the ones illustrated in Figure 8. Interestingly, most of these concepts were also evaluated very highly when companies had to determine the current maturity level and the target level. This led to the conclusion that the most promising concepts are not completely new to them and that they are already targeting to increase their competences in these fields. The only concept that was not mentioned before in Figure 7 was cybersecurity. This led to the hypothesis that SMEs are already aware of the future importance of cybersecurity, but they do not feel they are at a good level and also fail to raise their level in this area. 
In the third step of the field study, we combined the average data of the Industry 4.0 gap and the identified potential to generate the norm strategy matrix (see Figure 9). In principle, it can be seen that none of the Industry 4.0 concepts mentioned had a low potential and a large gap in implementation. This means that it makes sense to introduce all of the 42 concepts in the long term. There are a few so-called "low hanging fruits" that have a moderate potential with little effort for introducing the target level (which might be high or moderate according to the needs of SMEs). Examples of such concepts are additive manufacturing, servitization and sharing economy, digital upgrade, freemium, or artificial intelligence. It might sound surprising that a technology like artificial intelligence is clustered as a low hanging fruit technology. Here, it must be specified that SMEs in this field study defined a relatively low target level for artificial intelligence. The matrix also showed some concepts that can only be implemented with great effort, but which require a long-term "must have" strategy due to their high potential. Examples for this norm strategy are big data analytics, predictive maintenance, collaborative robotics, real-time monitoring systems, digitalized workplaces, improvement of their ERP, the introduction of MES systems, as well as a cultural change of the company towards developing an Industry 4.0 roadmap and qualifying their people with Training 4.0. The large number of Industry 4.0 concepts mentioned fall within the norm strategy "quick wins", which means that the effort for introduction is relatively moderate, but the concepts show a high potential. Examples of concepts where it makes sense to apply this strategy are agile manufacturing systems, automation, e-kanban, operator 4.0, simulation, cloud computing, smart assistance systems, as well as appropriate cybersecurity solutions for SMEs.

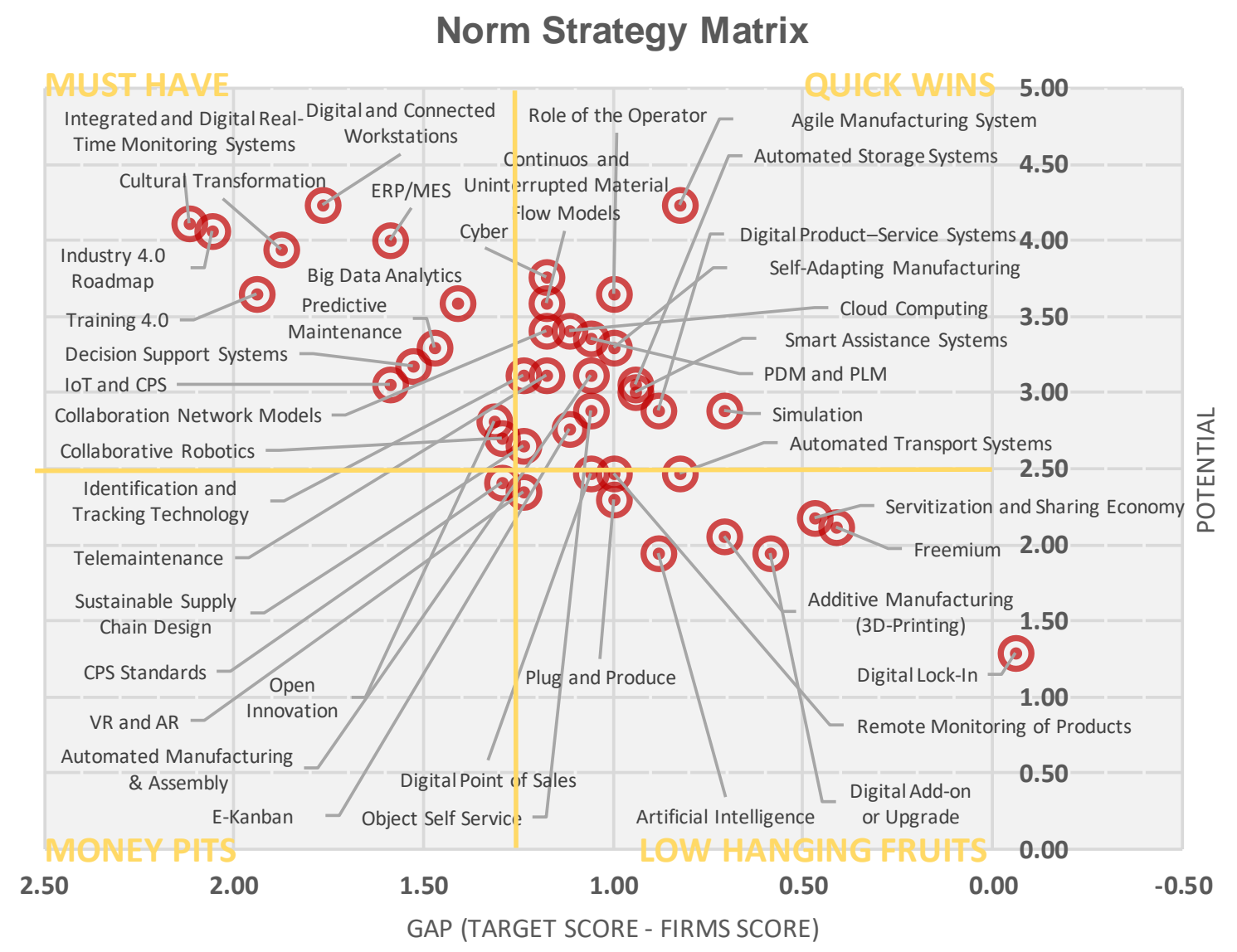

Figure 9. Norm strategy matrix with average values of the Industry 4.0 gap and the potential in the field study.

The norm strategy matrix illustrated in Figure 9 supports SMEs to plan short-term, medium-term, as well as long-term-oriented measures for introducing Industry 4.0 in their company. Thus, the application of the assessment model with a subsequent definition of norm strategies is recommended. 
Finally, we asked the participating SMEs about the usability of the assessment model and feedback for improvement. All participants found the assessment to be very instructive and a good exercise for thinking about the status of Industry 4.0 in their own company. Concerning the number of items to be evaluated, the participants were not all of the same opinion. Most felt it very positive that an Industry 4.0 concept catalog was provided to get a better overview of existing Industry 4.0 concepts. However, the catalog of 42 Industry 4.0 concepts requires a lot of time to fill out the assessment, which was considered quite exhausting by the participants. According to the participants, there were no major difficulties in assigning the level of maturity due to the detailed description and examples provided in the assessment model. The companies found it very useful to have an overview in the form of an individual norm strategy matrix at the end of the assessment, as this supported the definition of future Industry 4.0 measures and projects. All in all, the participants found the assessment to be effortful to conduct, but extremely useful for paving the way to implement Industry 4.0 in a systematic manner in the company.

\section{Discussion}

\subsection{Novel Aspects of the Proposed Assessment Model}

As described in the introduction and review in Section 3.1, our assessment model differs from existing models. While general assessment models [13-15] (developed for both SMEs and large companies) are often limited to a general Likert scale assessment, our model offers a significant advantage for smaller companies. The additional detailed description of each maturity level for each Industry 4.0 concept (including practical examples) makes it easier for SMEs to determine their own maturity level. This assistance is particularly important as many SMEs do not have highly qualified employees who have experience with all concepts. Another advantage over all previous models is the depth and number of Industry 4.0 concepts that can be evaluated, which means that many companies doing the assessment even start to think about certain perhaps less well-known concepts. Finally, we saw the subsequent derivation of the norm strategy matrix as a decisive difference and novelty of our model, since it is a practical aid especially for SMEs in the selection and introduction of important Industry 4.0 concepts for each individual firm.

\subsection{Implications for Academia and Practitioners}

For research purposes, the presented assessment model represents an extension and enrichment of already existing assessment models for Industry 4.0. On the one hand, the proposed model is designed for use in SMEs and has also been developed and tested with the involvement of SMEs. On the other hand, the implementation of Industry 4.0 in the whole company or parts of the company is not just evaluated superficially, but existing Industry 4.0 concepts are specifically evaluated on a very detailed level. On the one hand, this type of evaluation goes much deeper than all other currently existing models and at the same time offers a catalog of 42 Industry 4.0 concepts, which have been determined based on scientific contributions. For future research, the assessment model offers the possibility to examine the implementation of the Industry 4.0 concepts in detail. If the assessment is carried out in the future with a sufficient number of SMEs from different industrial sectors, these data can be used for many purposes. For example, it will be possible to determine which Industry 4.0 concepts are most important for different company sizes. In addition, this analysis can also be reduced to individual industrial sectors to understand where and why different dimensions of SMEs or different industrial sectors gave a different assessment. The same analysis can also be extended to the current and target maturity level. Finally, it is a new and original approach, as the assessment of an Industry 4.0 gap and its potential is combined in a norm strategy matrix.

For practitioners from SMEs, the assessment model is an ideal tool to evaluate the current situation of the company and to systematically plan future projects and initiatives. One of the biggest advantages for SMEs is the Industry 4.0 catalog with different concepts and technologies, which also helps small 
companies to get an overview of Industry 4.0 methods. The validation in practice has shown that the model can be applied in small companies, although the evaluation itself takes some time. The subsequent systematic analysis of the Industry 4.0 gaps and the potential in the norm strategy matrix especially serves SMEs as an orientation guide to better plan future initiatives and to transfer them into an implementation plan for Industry 4.0. The application of the assessment model provides companies practical recommendations for the application of selected Industry 4.0 concepts and how and with which priority they should be implemented.

\subsection{Limitations of the Proposed Assessment Model}

Despite the many advantages mentioned, the model has certain limitations. One limitation is certainly the already mentioned effort for the evaluation. The validation phase has shown that most companies spend about one to two hours on the evaluation and usually also bring in experts from different areas of the company. Therefore, the user must invest the necessary time to be able to draw the right conclusions from the results. Furthermore, it can be limited if only one person carries out the evaluation because a certain subjective opinion cannot be excluded. Therefore, it is recommended that a team completes the evaluation to improve not only the quality of the answers but also the objectivity of the result. A third limitation to be mentioned is the catalog of 42 Industry 4.0 concepts used as a basis. In the course of the four-year research project from 2017-2020, a literature analysis was conducted to identify existing Industry 4.0 concepts until 2017. A first check by the research team after the development of the model in 2018 and its validation in 2019 showed that the Industry 4.0 concepts are still up-to-date and can be used in this way. However, it cannot be excluded that a few Industry 4.0 concepts might be added in the meantime. The proposed assessment model can be applied to every kind of industry sector. In the sample of SMEs we used for validation there were many different industrial sectors and the model could be used successfully in each of the industries. Of course the proposed model provides a catalog of 42 Industry 4.0 concepts, which not all might be of interest in each sector. This can easily be handled as the companies can assess the importance for their individual company as very low.

\section{Conclusions}

Industry 4.0 is a chance for SMEs to achieve a new level of competitiveness. Many SMEs are already trying to implement Industry 4.0 [28], but there is still a lack of specific instruments for introducing them $[29,30]$. In this paper, a maturity level-based assessment model for SMEs is presented. The model is based on 42 Industry 4.0 concepts identified by literature analysis, which are rated on a Likert scale of 1 to 5 . In addition to the current maturity level, a target level and the importance and potential of the Industry 4.0 concepts are evaluated by the user. The collected results show in a developed norm strategy matrix, which of the Industry 4.0 concepts should be approached immediately and which may need more time or are not immediately implemented due to a lower potential.

The proposed assessment model shows several advantages compared to already existing models. It provides a detailed overview of existing Industry 4.0 concepts and is very easy for SMEs to adopt. The evaluation of the maturity level is facilitated through a brief description of the five maturity levels for each of the 42 Industry 4.0 concepts. Further, the evaluation and combination of a target level and the potential of each of the Industry 4.0 concepts in the norm strategy matrix allow SMEs to plan and schedule the implementation of Industry 4.0 in a very systematic way.

Further research is planned in the development of a web-based version of the assessment model and its dissemination in SMEs (ongoing work). As soon as enough SMEs complete the assessment model online and allow the use and processing of the anonymized data the research team plans to use these data for further analysis and a benchmarking functionality. In its final version, the assessment model will also show SMEs their position for each Industry 4.0 concept compared to those of the average of companies of a similar size and the same industrial sector. This will allow SMEs to better 
identify their own competitive situation and researchers to better understand the implementation of Industry 4.0 for each company size and industrial sector as well as its development over the time.

Author Contributions: E.R. led the research team, developed the structure of the maturity level-based assessment model, and conducted the field study for testing and validation purposes; M.U. worked on the literature review and the development of the maturity level-based assessment model; R.A.R. and L.G. contributed to the literature review and screening process as well as in the content analysis; M.W. conducted the analysis of field study data; D.T.M. supervised the work as scientific coordinator of the research project. All authors have read and agreed to the published version of the manuscript.

Funding: This project has received funding from the European Union's Horizon 2020 R\&I programme under the Marie Skłodowska-Curie grant agreement No 734713.

Acknowledgments: This work belongs to the project "SME 4.0 - Industry 4.0 for SMEs" (funded in the European Union's Horizon 2020 R\&I program under the Marie Skłodowska-Curie grant agreement No 734713). The authors would like to thank all industrial companies that contributed to the field study.

Conflicts of Interest: The authors declare no conflict of interest.

\section{References}

1. Matt, D.T. Design of lean manufacturing support systems in make-to-order production. Key Eng. Mater. 2009, 410, 151-158. [CrossRef]

2. Dallasega, P.; Rauch, E.; Matt, D.T. Sustainability in the supply chain through synchronization of demand and supply in ETO-companies. Procedia CIRP 2015, 29, 215-220. [CrossRef]

3. Kagermann, H.; Helbig, J.; Hellinger, A.; Wahlster, W. Recommendations for Implementing the Strategic Initiative INDUSTRIE 4.0: Securing the Future of German Manufacturing Industry; Final report of the Industrie 4.0 Working Group; Forschungsunion: Frankfurt am Main, Germany, 2013.

4. Zhou, K.; Liu, T.; Zhou, L. Industry 4.0: Towards future industrial opportunities and challenges. In Proceedings of the 12th International Conference on Fuzzy Systems and Knowledge Discovery (FSKD), Zhangiajie, China, 15-17 August 2015; IEEE: Piscataway, NJ, USA, 2015; pp. 2147-2152.

5. Lee, J.; Bagheri, B.; Kao, H.A. A cyber-physical systems architecture for industry 4.0-based manufacturing systems. Manuf. Lett. 2015, 3, 18-23. [CrossRef]

6. Lee, J. Industry 4.0 in big data environment. Ger. Harting Mag. 2013, 1, 8-10.

7. Kang, H.S.; Lee, J.Y.; Choi, S.; Kim, H.; Park, J.H.; Son, J.Y.; Kim, B.H.; Do Noh, S. Smart manufacturing: Past research, present findings, and future directions. Int. J. Precis. Eng. Manuf. Green Technol. 2016, 3, 111-128. [CrossRef]

8. Thoben, K.D.; Wiesner, S.; Wuest, T. Industrie 4.0" and smart manufacturing-a review of research issues and application examples. Int. J. Autom. Technol. 2017, 11, 4-16. [CrossRef]

9. Rojas, R.A.; Rauch, E. From a literature review to a conceptual framework of enablers for smart manufacturing control. Int. J. Adv. Manuf. Technol. 2019, 104, 517-533. [CrossRef]

10. Hübner, M.; Liebrecht, C.; Malessa, N.; Kuhnle, A.; Nyhuis, P.; Lanza, G. A process model for implementing Industry 4.0-Introduction of a process model for the individual implementation of Industry 4.0 methods. Wt Werkstattstech. 2017, 107, 266-272.

11. Matt, D.T.; Rauch, E.; Riedl, M. Knowledge Transfer and Introduction of Industry 4.0 in SMEs: A Five-Step Methodology to Introduce Industry 4.0. In Analyzing the Impacts of Industry 4.0 in Modern Business Environments; Brunet-Thornton, R., Martinez, F., Eds.; IGI Global: Hershey, PA, USA, 2018; pp. 256-282.

12. Anderl, R.; Picard, A.; Wang, Y.; Fleischer, J.; Dosch, S.; Klee, B.; Bauer, J. Guideline Industrie 4.0—Guiding Principles for the Implementation of Industrie 4.0 in Small and Medium Sized Businesses. VDMA. Available online: https://industrie40.vdma.org/documents/4214230/0/Guideline\%20Industrie\%204.0.pdf/70abd403cb04-418a-b20f-76d6d3490c05 (accessed on 12 March 2018).

13. Schumacher, A.; Erol, S.; Sihn, W. A maturity model for assessing Industry 4.0 readiness and maturity of manufacturing enterprises. Procedia CIRP 2016, 52, 161-166. [CrossRef]

14. Jentsch, D.; Riedel, R.; Jäntsch, A.; Müller, E. Factory audit for industry 4.0—Strategic approach for capability assessment and gradual introduction of a smart factory (in German: Fabrikaudit Industrie 4.0: Strategischer Ansatz zur Potenzialermittlung und schrittweisen Einführung einer Smart Factory). Zwf Z. Für Wirtsch. Fabr. 2013, 108, 678-681. [CrossRef] 
15. Ganzarain, J.; Errasti, N. Three stage maturity model in SME's toward industry 4.0. J. Ind. Eng. Manag. 2016, 9, 1119-1128. [CrossRef]

16. Mittal, S.; Romero, D.; Wuest, T. Towards a Smart Manufacturing Maturity Model for SMEs. In Advances in Production Management Systems; Moon, I., Lee, G., Park, J., Kiritsis, D., von Cieminski, G., Eds.; Springer: Cham, Switzerland, 2018; Volume 536, pp. 155-163.

17. Bittighofer, D.; Dust, M.; Irslinger, A.; Liebich, M.; Martin, L. State of Industry 4.0 Across German Companies. In Proceedings of the IEEE International Conference on Engineering, Technology and Innovation 2018, Stuttgart, Germany, 17-20 June 2018; IEEE: Piscataway, NJ, USA, 2018; pp. 1-8.

18. Puchan, J.; Zeifang, A.; Leu, J.D. Industry 4.0 in practice-identification of industry 4.0 success patterns. In Proceedings of the IEEE International Conference on Industrial Engineering and Engineering Management (IEEM 2018), Bangkok, Thauiland, 16-19 December 2018; IEEE: Piscataway, NJ, USA, 2018; pp. 1091-1095.

19. Trotta, D.; Garengo, P. Assessing Industry 4.0 Maturity: An Essential Scale for SMEs. In Proceedings of the 8th International Conference on Industrial Technology and Management (ICITM 2019), Cambridge, UK, 2-4 March 2019; IEEE: Piscataway, NJ, USA, 2019; pp. 69-74.

20. Pirola, F.; Cimini, C.; Pinto, R. Digital readiness assessment of Italian SMEs: A case-study research. J. Manuf. Technol. Manag. 2019. [CrossRef]

21. Hamidi, S.R.; Aziz, A.A.; Shuhidan, S.M.; Aziz, A.A.; Mokhsin, M. SMEs maturity model assessment of IR4. 0 digital transformation. In Advances in Intelligent Systems and Computing, Proceedings of the 7th International Conference on Kansei Engineering and Emotion Research 2018, KEER 2018, Kuching, Malaysia, 19-22 March 2018; Lokman, A., Yamanaka, T., Lévy, P., Chen, K., Koyama, S., Eds.; Springer: Singapore, 2018; Volume 739, pp. 721-732.

22. Sheen, D.P.; Yang, Y. Assessment of Readiness for Smart Manufacturing and Innovation in Korea. In Proceedings of the 2018 IEEE Technology and Engineering Management Conference (TEMSCON), Evanston, IL, USA, 28 June-1 July 2018; IEEE: Piscataway, NJ, USA, 2018; pp. 1-5.

23. Chonsawat, N.; Sopadang, A. The Development of the Maturity Model to evaluatethe Smart SMEs 4.0 Readiness. In Proceedings of the International Conference on Industrial Engineering and Operations Management, Bangkok, Thailand, 5-7 March 2019; IEOM: Bangkok, Thailand, 2019; pp. 354-363.

24. Brozzi, R.; D’Amico, R.D.; Monizza, G.P.; Marcher, C.; Riedl, M.; Matt, D. Design of Self-assessment Tools to measure industry 4.0 readiness. A methodological approach for craftsmanship SMEs. In Proceedings of the IFIP International Conference on Product Lifecycle Management 2018, Turin, Italy, 2-4 July 2018; Springer: Cham, Switzerland, 2018; pp. 566-578.

25. Schiffer, M.; Wiendahl, H.H.; Saretz, B. Self-assessment of Industry 4.0 Technologies in Intralogistics for SME's. In Proceedings of the IFIP International Conference on Advances in Production Management Systems 2019, Austin, TX, USA, 1-5 September 2019; Springer: Cham, Switzerland, 2019; pp. 339-346.

26. Krowas, K.; Riedel, R. Planning Guideline and Maturity Model for Intra-logistics 4.0 in SME. In Proceedings of the IFIP International Conference on Advances in Production Management Systems 2019, Austin, TX, USA, 1-5 September 2019; Springer: Cham, Switzerland, 2019; pp. 331-338.

27. Kolla, S.S.V.K.; Minoufekr, M.; Plapper, P. Deriving essential components of lean and industry 4.0 assessment model for manufacturing SMEs. Procedia CIRP 2019, 81, 753-758. [CrossRef]

28. Rauch, E.; Stecher, T.; Unterhofer, M.; Dallasega, P.; Matt, D.T. Suitability of Industry 4.0 Concepts for Small and Medium Sized Enterprises: Comparison between an Expert Survey and a User Survey. In Proceedings of the International Conference on Industrial Engineering and Operations Management, Bangkok, Thailand, 5-7 March 2019.

29. Saxena, P.; Papanikolaou, M.; Pagone, E.; Salonitis, K.; Jolly, M.R. Digital Manufacturing for Foundries 4.0. In Light Metals 2020; Springer: Cham, Switzerland, 2020; pp. 1019-1025.

30. Matt, D.T.; Rauch, E. SME 4.0: The Role of Small-and Medium-Sized Enterprises in the Digital Transformation. In Industry 4.0 for SMEs; Palgrave Macmillan: Cham, Switzerland, 2020; pp. 3-36.

(C) 2020 by the authors. Licensee MDPI, Basel, Switzerland. This article is an open access article distributed under the terms and conditions of the Creative Commons Attribution (CC BY) license (http://creativecommons.org/licenses/by/4.0/). 